\title{
Unilateral re-expansion pulmonary edema following treatment of pneumothorax with exceptionally massive sputum production, followed by circulatory collapse
}

\author{
Teruya Komatsu MD¹, Sumiya Shibata MD¹, Ryutaro Seo MD², Keisuke Tomii MD², \\ Kyousuke Ishihara MD², Takurou Hayashi MD³, Yutaka Takahashi MD
}

T Komatsu, S Shibata, R Seo, et al. Unilateral re-expansion pulmonary edema following treatment of pneumothorax with exceptionally massive sputum production, followed by circulatory collapse. Can Respir J 2010;17(2):53-55.

A case of a 61-year-old man who developed ipsilateral re-expansion pulmonary edema after pleural drainage for a right pneumothorax is described. The patient's chest $\mathrm{x}$-ray revealed a totally collapsed right lung. After insertion of a chest drainage tube, he began to produce a moderate amount of serous, yellowish sputum. Despite continuous positive airway pressure support, his dyspnea gradually worsened and his oxygenation could not be maintained; therefore, to improve his hypoxemic state, intubation was necessary. His chest $\mathrm{x}$-ray following chest tube insertion showed ipsilateral diffuse infiltrates. These radiographic and physical findings were consistent with re-expansion pulmonary edema. The present case was complicated by extreme hypotension and tachycardia due to massive fluid loss. His condition gradually improved with invasive mechanical ventilation. Re-expansion pulmonary edema is an uncommon complication of pleural drainage for pneumothorax, and therapy is supportive. In the present case, the exceptional severity of the pulmonary edema, as well as its general concept, is reviewed in accordance with other relevant literature.

Key Words: Circulatory collapse; Mortality; Pleural drainage; Pneumothorax; Re-expansion pulmonary edema

$\mathrm{R}$ e-expansion pulmonary edema is a rare complication of pleural drainage for pneumothorax or pleural effusion. Adegboye et al (1) reported an incidence rate of $0.8 \%$. Theoretically, increased vascular permeability, diminished surfactant production and structural damage are believed to cause re-expansion pulmonary edema; however, none of these factors have been proven (2-4). We present a case of massive re-expansion pulmonary edema after insertion of a thoracic drainage tube for pneumothorax.

\section{CASE PRESENTATION}

A 61-year-old man was referred to the Kobe City Medical Center General Hospital (Kobe, Japan) for a right pneumothorax; otherwise, he had never seen a doctor. Due to a mild clinical symptom, which was dry cough lasting for a few days, the duration of his right pneumothorax was unknown. Until he quit one year previously, he had a 30 pack-year history of smoking. Physical examination revealed absent breath sounds over
Un œdème pulmonaire unilatéral de réexpansion après le traitement d'un pneumothorax comportant une production exceptionnellement massive d'expectorations, suivi d'un collapsus circulatoire

Les auteurs décrivent le cas d'un homme de 61 ans qui a développé un œdème pulmonaire ipsilatéral de réexpansion après le drainage pleural d'un pneumothorax droit. La radiographie pulmonaire du patient a révélé un collapsus complet du poumon droit. Après l'insertion d'une sonde de drainage pulmonaire, il a commencé à produire une quantité modérée d'expectorations séreuses et jaunâtres. Malgré une pression positive continue, la dyspnée s'est graduellement aggravée, et on ne parvenait pas à maintenir son oxygénation. Il a donc fallu l'intuber pour améliorer son état hypoxémique. La radiographie pulmonaire suivant l'insertion de la sonde pulmonaire a révélé des infiltrats ipsalatéraux diffus. Ces observations radiographiques et physiques étayaient un œè̀me pulmonaire de réexpansion. Le présent cas était compliqué par une hypotension et une tachycardie extrêmes attribuables à une perte massive de liquide. L'état du patient s'est graduellement amélioré grâce à une ventilation mécanique effractive. L'œdème pulmonaire de réexpansion est une complication peu courante du drainage pleural d'un pneumothorax qui exige un traitement d'appoint. Dans le cas présent, la gravité exceptionnelle de l'œdème pulmonaire, de même que son concept général, est analysée conformément aux autres publications pertinentes.

the right hemithorax. A chest $\mathrm{x}$-ray revealed a completely collapsed right lung (Figure 1). Even with a totally collapsed right lung, he only complained about moderate dry cough, without dyspnea. A $20 \mathrm{Fr}$ chest drainage tube was inserted through the fourth intercostal space at the anterior axillary line, which was put on wall suction of $-15 \mathrm{cmH}_{2} \mathrm{O}$. The right lung was confirmed to be well re-expanded radiologically; however, the patient started to produce serous yellowish sputum, followed by gradually worsening dyspnea. Approximately $3 \mathrm{~h}$ after tube insertion, adequate blood oxygen levels could not be maintained in the patient. Therefore, respiratory support was switched from noninvasive positive pressure ventilation to mechanical ventilation under tracheal intubation. A chest $\mathrm{x}$-ray showed diffuse, dense opacification on the right pulmonary field, consistent with severe pulmonary edema (Figure 2). Importantly, the amount of sputum suctioned from the tracheal tube was considerable (Figure 3) (approximately $1000 \mathrm{~mL}$ within the first $5 \mathrm{~h}$ ), with arterial blood pressure decreasing to

${ }^{1}$ Department of General Thoracic Surgery; ${ }^{2}$ Department of Respiratory Medicine; ${ }^{3}$ Department of Emergency Medicine, Kobe City Medical Center General Hospital, Kobe, Japan

Correspondence: Dr Teruya Komatsu, Division of Thoracic and Esophageal Surgery, Department of Surgery, Queen Elizabeth II Health Science

Centre, 7S-012 1278 Tower Road, Halifax, Nova Scotia B3H 2Y9. Telephone 902-473-5602, e-mail tokushucross@hotmail.com 


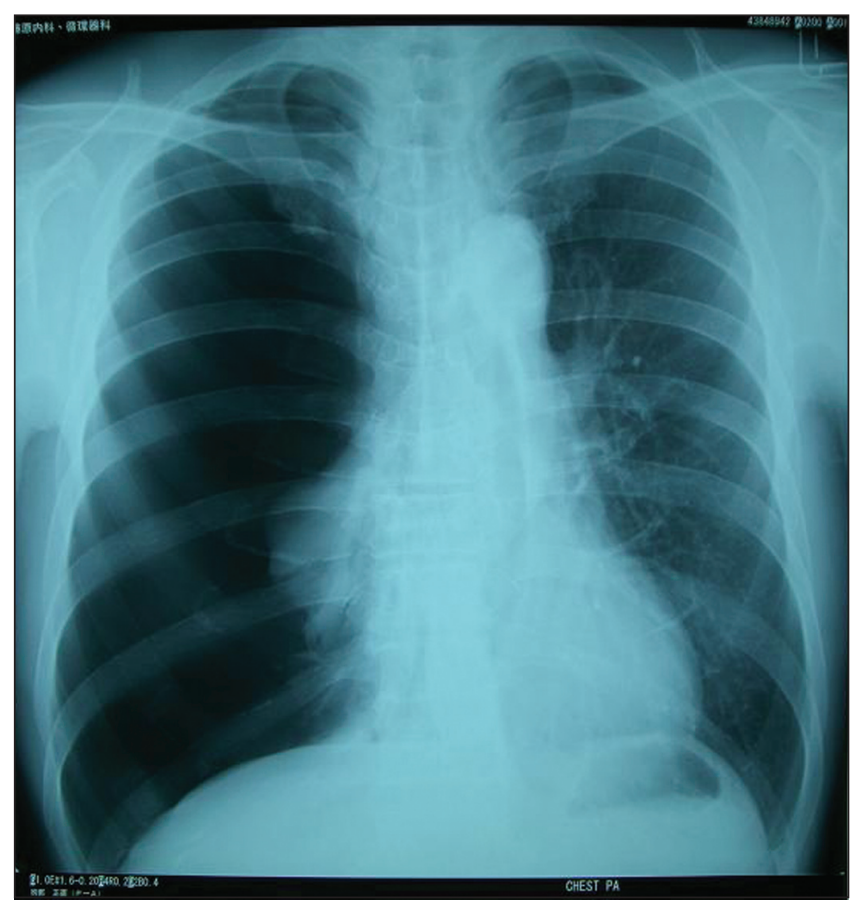

Figure 1) Chest $x$-ray showing a totally collapsed right lung on admission

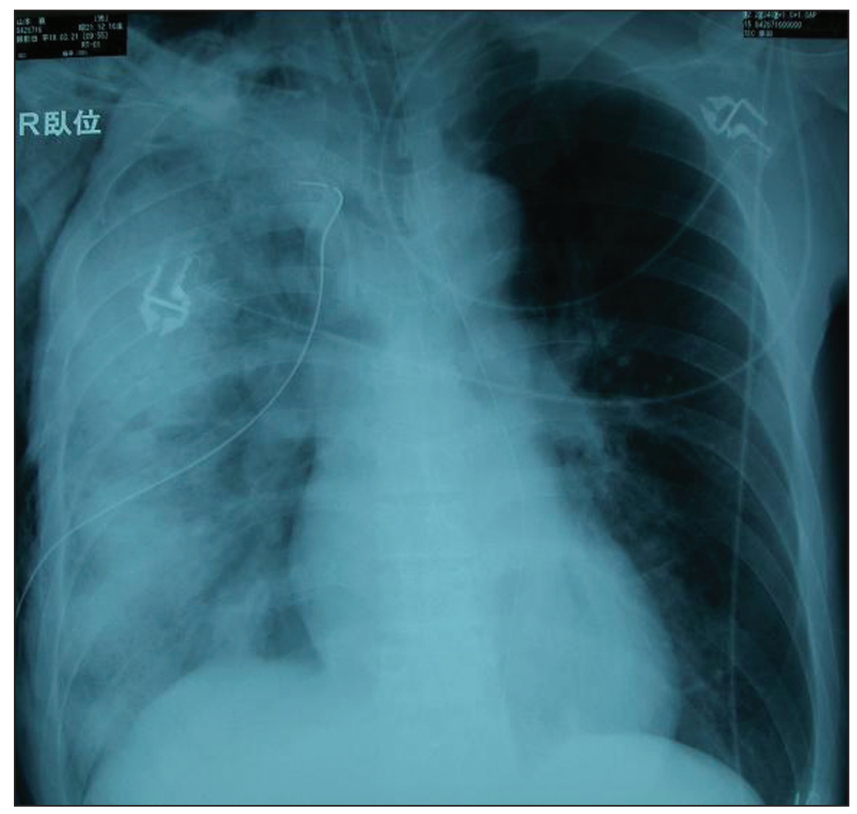

Figure 2) Chest $x$-ray 3 h after thoracic tube insertion demonstrating ipsilateral pulmonary edema

$60 \mathrm{mmHg}$, signalling circulatory collapse. At this point, $5 \mathrm{~h}$ after the tube placement, blood albumin levels decreased to $0.022 \mathrm{~g} / \mathrm{L}$. In addition to maintenance crystalloid fluid infusion at $250 \mathrm{~mL} / \mathrm{h}$, colloid boluses ( $1500 \mathrm{~mL}$ of $5 \%$ albumin solution) were administered to maintain the circulation. The patient showed gradual improvement with a vigorous three-day treatment of positive pressure ventilation (peak positive end-expiratory pressure of $20 \mathrm{mmHg}$ ). Oxygen administration was ceased one day after extubation. The thoracostomy tube was removed without complication and the patient was discharged 14 days after admission. The chest $\mathrm{x}$-ray revealed clearing of the pulmonary edema on the day of hospital discharge (Figure 4).

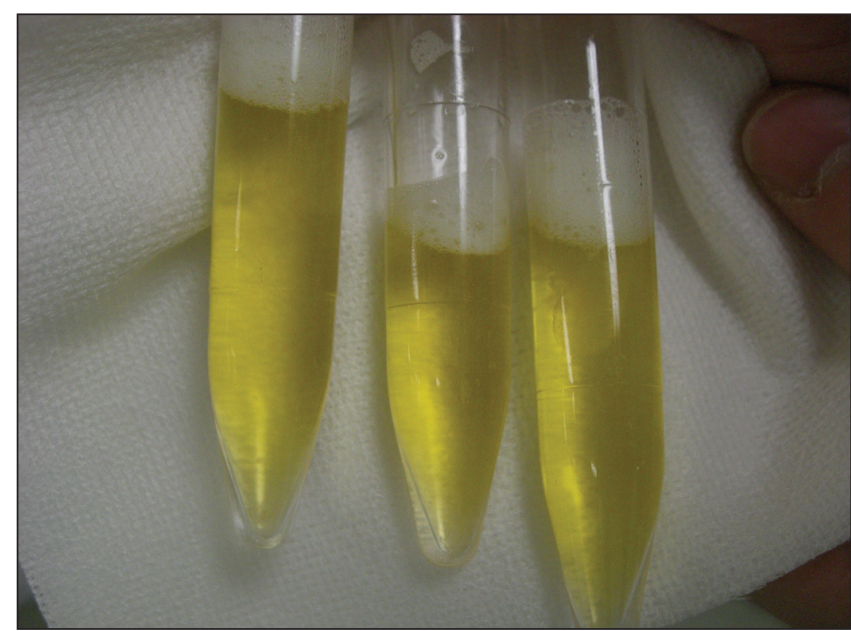

Figure 3) Clear, yellowish fluid collected from the right lung. Total protein concentration in this fluid was $0.033 \mathrm{~g} / \mathrm{L}$

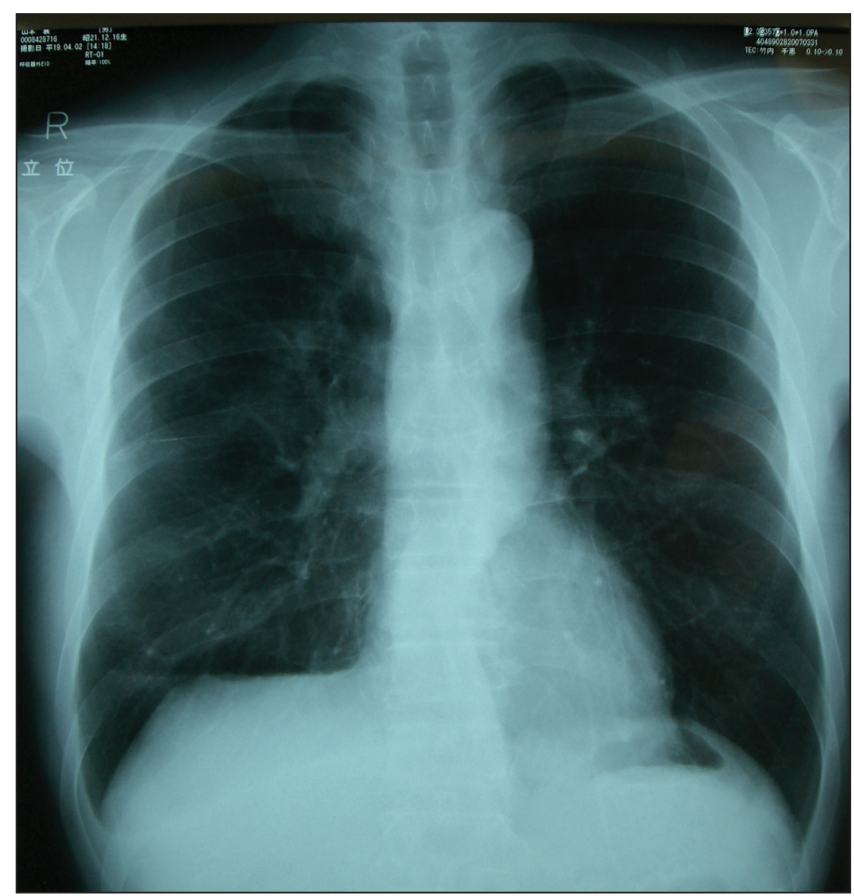

Figure 4) Chest $x$-ray on discharge showing complete resolution of pulmonary edema

\section{DISCUSSION}

Re-expansion pulmonary edema, which was first reported by Carlson et al (5) in 1958, is an uncommon complication of tube thoracostomy for pneumothorax and, once it occurs, may lead to severe hypoxemia, with mortality as high as 20\% (5-7). Furthermore, the majority of fatal cases are associated with bilateral pulmonary edema.

Re-expansion pulmonary edema develops almost immediately after resolution of a pneumothorax and is usually ipsilateral (2). The risk of re-expansion pulmonary edema is believed to be highest after rapid re-expansion of a lung that has been collapsed for more than three days $(6,8)$. Other risk factors including young age, a large pneumothorax and the method of re-expansion, may help predict which patients encounter this complication (2). In their series, Matsuura et al (8) reported a 
statistically significant increased incidence of re-expansion pulmonary edema in patients 20 to 39 years of age. According to a report by Murphy and Tomlanovich (9), slow resolution of a collapsed lung by low negative pressure suction could be beneficial; however, this was not addressed scientifically.

A definitive mechanism has yet to be elucidated; however, increased vascular permeability, which is caused by hypoxic injury to the capillary and alveolar membrane, diminished surfactant production and structural damage, is believed to be causative $(2-4)$.

After chest tube insertion in the present case, the tube was put to water seal and, a few minutes later, was connected to negative pressure suction of $15 \mathrm{cmH}_{2} \mathrm{O}$. In retrospect, this may not have been necessary because keeping the chest tube on water seal was likely enough for the collapsed lung to be re-expanded.

Symptoms include mild to severe respiratory distress that typically begins within $5 \mathrm{~h}$ after lung re-expansion, with the

\section{REFERENCES}

1. Adegboye VO, Falade A, Osinusi Kobajimi MO. Reexpansion pulmonary oedema as a complication of pleural drainage. Niger Postgrad Med J 2002;9:214-20.

2. Gordon AH, Grant GP, Kaul SK. Reexpansion pulmonary edema after resolution of tension pneumothorax in the contralateral lung of a previously lung injured patient. J Clin Anesth 2004;16:289-92.

3. Sivrikoz MC, Tuncozgur B, Cekmen M, et al. The role of tissue reperfusion in the reexpansion injury of the lungs. Eur J Cardiothorac Surg 2002;22:721-7.

4. DuBose J, Perciballi J, Timmer S, Kujawaski EJ. Bilateral reexpansion pulmonary edema after treatment of spontaneous pneumothorax. Curr Surg 2004;61:376-9.

5. Carlson RI, Classen KL, Gollan F, Gobbel WG Jr, Sherman DE, Christensen RO. Pulmonary edema following the rapid reexpansion of a totally collapsed lung due to a pneumothorax: A clinical and experimental study. Surg Forum 1958;9:367-71.

6. Mahfood S, Hix WR, Aaron BL, Blaes P, Watson DC. Reexpansion pulmonary edema. Ann Thorac Surg 1988;45:340-5.

7. Sherman SC. Reexpansion pulmonary edema: A case report and review of the current literature. J Emerg Med 2003;24:23-7. presence of rales in the affected lung field and frothy sputum production $(2,10)$. Supportive therapy is the rule, with some patients requiring noninvasive positive airway pressure or intubation, followed by vasopressor support and vigorous fluid resuscitation $(2,11,12)$. In cases of unilateral re-expansion pulmonary edema, changing the patient's position to the lateral decubitus position with the affected side up is also effective due to the reduction of intrapulmonary shunting $(2,13)$.

\section{CONCLUSION}

Re-expansion pulmonary edema is a rare complication of tube thoracostomy for pneumothorax. According to reports, high-risk patients are younger and with a total or severe lung collapse of longer duration. Although no evidence to support a preferred preventive method for this complication is available, the collapsed lung should be re-expanded as slowly as possible, for example, by connecting the chest tube to water seal. Once this occurs, treatment is mostly supportive, regardless of severity.

8. Matsuura Y, Nomimura T, Murakami H, Matsushima T, Kakehashi M, Kajihara H. Clinical analysis of reexpansion pulmonary edema. Chest 1991;100:1562-6.

9. Murphy K, Tomlanovich MC. Unilateral pulmonary edema after drainage of a spontaneous pneumothorax: Case report and review of the world literature. J Emerg Med 1983;1:29-36.

10. Beng ST, Mahadevan M. An uncommon life-threatening complication after chest tube drainage of pneumothorax in the ED. Am J Emerg Med 2004;22:615-9.

11. Volpicelli G, Fogliati C, Radeschi G, Frascisco M. A case of unilateral re-expansion pulmonary oedema successfully treated with non-invasive continuous positive airway pressure. Eur J Emerg Med 2004;11:291-4.

12. Iqbal M, Multz A S, Rossoff LJ, Lackner RP. Reexpansion pulmonary edema after VATS successfully treated with continuous positive airway pressure. Ann Thorac Surg 2000;70:669-71.

13. Trachiotis GD, Vricella LA, Aaron BL, Hix WR. As originally published in 1988: Reexpansion pulmonary edema. Updated in 1997. Ann Thorac Surg 1997;63:1206-7. 


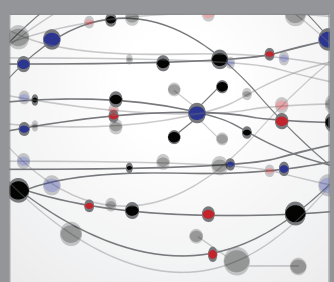

The Scientific World Journal
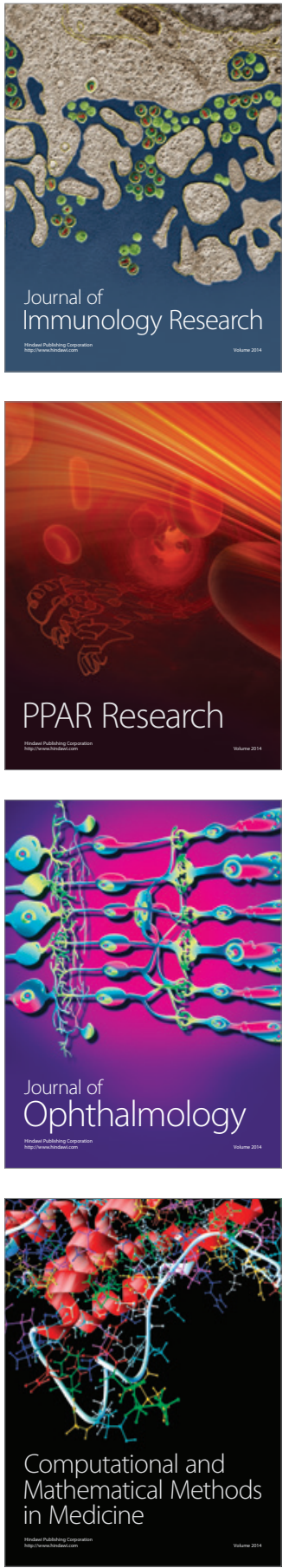

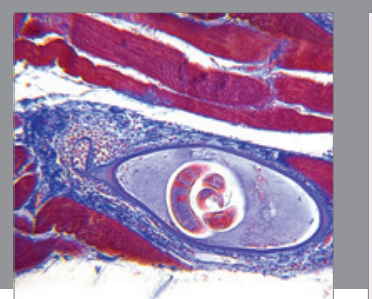

Gastroenterology Research and Practice

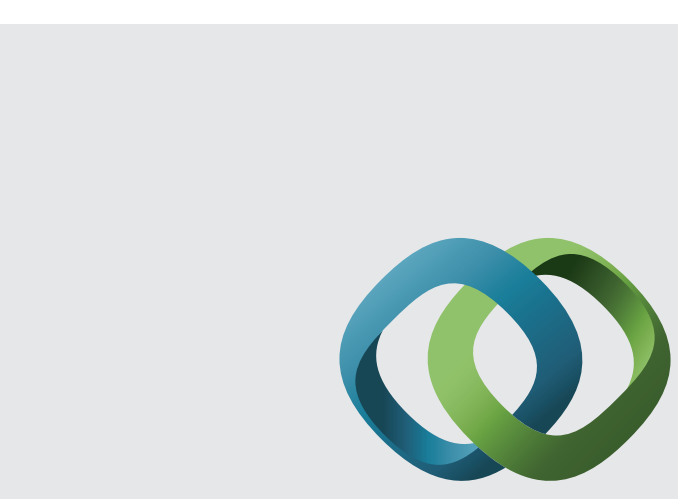

\section{Hindawi}

Submit your manuscripts at

http://www.hindawi.com
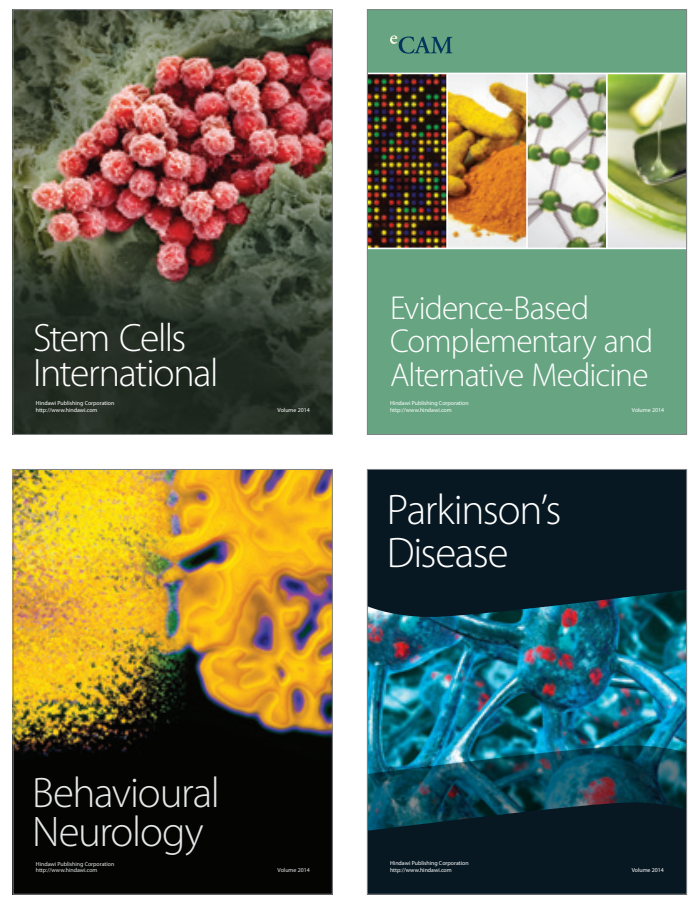
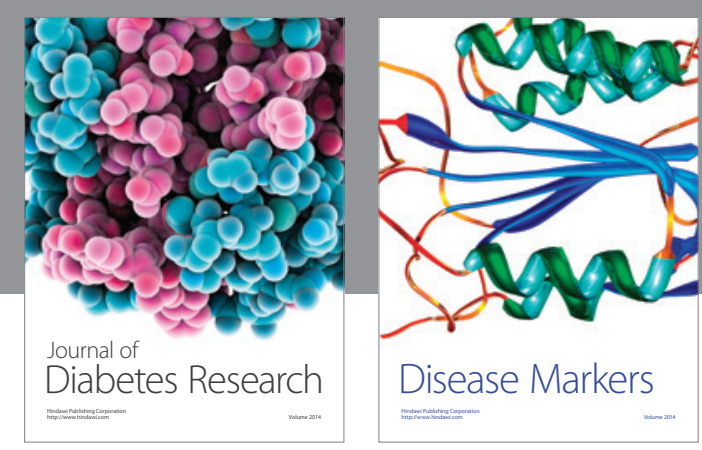

Disease Markers
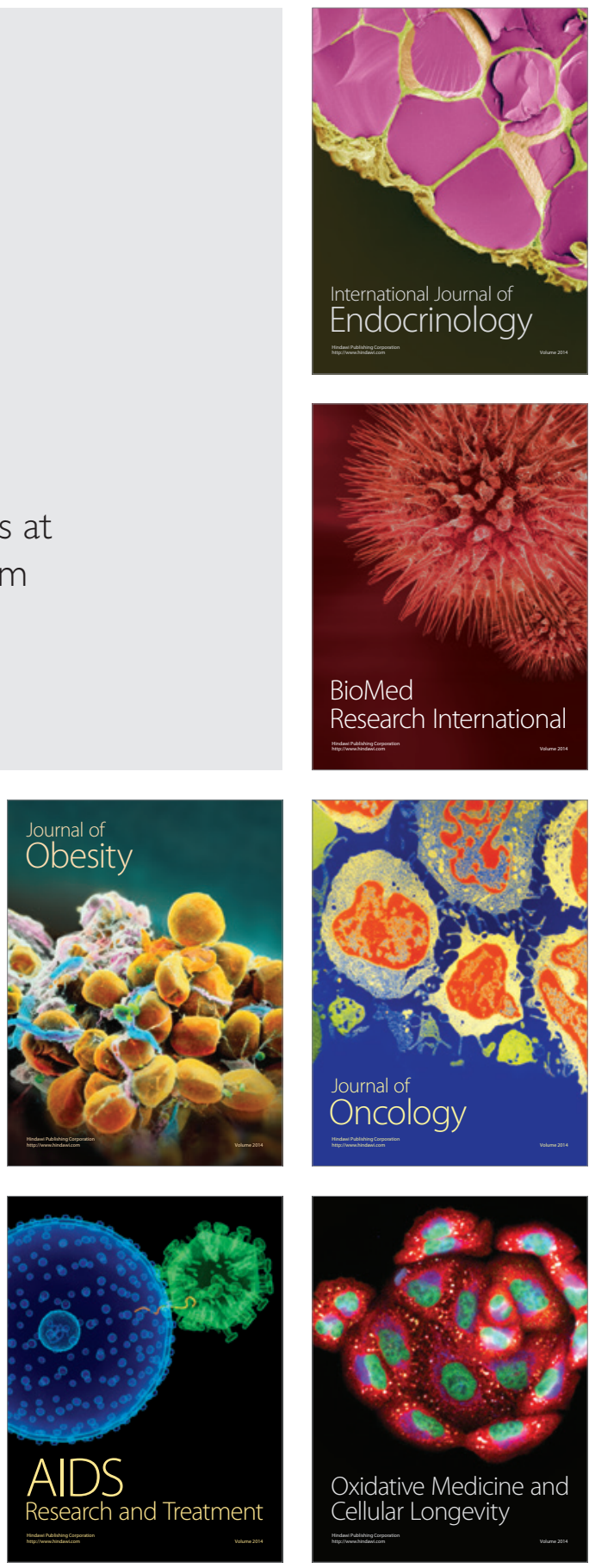